\title{
Comparison of single shot caudal Ropivacaine and Bupivacaine in paediatric patients undergoing herniotomy
}

\author{
Rishabh Ravi, MD; Bigen Man Shakya, MD; Megha Koirala, MD; Anil Shrestha, MD \\ Department of Anaesthesiology, Tribhuvan University Teaching Hospital, Maharajgunj Medical Campus, Institute of \\ Medicine, Kathmandu, Nepal
}

Corresponding author

Anil Shrestha, MD

Email: aanilsh@hotmail.com

Received 2 Dec 2019

Accepted 20 Dec 2019

\begin{abstract}
Background

Inguinal hernia repair is a common surgical procedure in children. Caudal block is an appropriate technique for the treatment of post operative pain in children undergoing herniotomy. This study compared the effects of Ropivacaine and Bupivacaine in caudal block in children undergoing herniotomy.
\end{abstract}

\section{Methodology}

A total of 74 patients between 5-16 yrs undergoing herniotomy were randomized in two groups. In Group B, $0.75 \mathrm{ml} / \mathrm{kg}$ of $0.25 \%$ caudal Bupivacaine was administered whereas Group R received 0.75 $\mathrm{ml} / \mathrm{kg}$ of $0.25 \%$ caudal Ropivacaine. Pain score was assessed using Wong Baker pain scale in post operative period and motor power was assessed using modified Bromage scale till 6 hours.

\section{Results}

The mean duration of post operative analgesia was found to be $253.51 \pm 11.48$ minutes in Bupivacaine and $258.1 \pm 12.10$ minutes in Ropivacaine group. The median duration of motor block was 180 (Q1 60- Q3 180) minutes in Bupivacaine and 30 (Q1 22.5- Q3 45) minutes in Ropivacaine group which was statistically significant. There was complete recovery of motor block by 2 hour in Ropivacaine and by 4 hour in Bupivacaine group. ( $p$ value $<0.001$ )

\section{Conclusion}

From the current study, it is concluded that caudal Ropivacaine at $0.25 \%$ concentration and $0.75 \mathrm{ml} /$ $\mathrm{kg}$ provides similar duration of post operative analgesia with less motor block in comparison to Bupivacaine.

Key words: Bupivacaine, Caudal, Postoperative analgesia, Ropivacaine.

\section{Introduction}

Herniotomy is a common procedure in paediatric population for the management of inguinal hernia. Abdominal wall incision is the cause of pain after hernia surgery. The frequency of moderate to severe pain is found to be $30-75 \%$ despite pain management methods ${ }^{1}$. Individual self-reporting is the preferred method of pain assessment, as pain is a subjective experience. Pain is difficult to assess in paediatric population due to communication issues. There are different clinical assessment tools and one of such kind is pictorial based pain scale. The Wong-Baker Faces scale is simple to use, freely available and can be used in children as young as 3 years of age ${ }^{2}$.

Acute postoperative pain management is based on four classes of analgesics, namely local anaesthetics used as local infiltration, regional nerve block 
and caudal block, opioids, non-steroidal antiinflammatory drugs (NSAIDs), and acetaminophen ${ }^{3}$. NSAIDS, though easily available and widely used, their analgesic potency is not enough to control post operative pain in some patients ${ }^{1}$. With opioids as the single modal therapy, there are chances of complications such as respiratory depression, nausea, and vomiting.

Caudal block provides excellent post-operative analgesia and attenuation of the stress response in infants and children ${ }^{3}$. Caudal analgesia is commonly used in paediatric patient for pain relief following infra umbilical and lower thoracic surgical procedure. The technique is relatively simple and safe ${ }^{4}$.

\section{Methodology}

This was a randomized, double blind, prospective, interventional study done in Tribhuvan University Teaching Hospital over a period of 1 year. The sample size was calculated using the formula $n=2\left(Z_{\alpha}+Z_{\beta}\right)^{2}$ $\mathrm{S}^{2} / \mathrm{d}^{2}$ where $\mathrm{Z} \alpha=1.96$ at $95 \%$ confidence interval $Z_{\beta}=0.84$ at $80 \%$ power. Assuming $d=8$ minutes of mean difference in duration of absolute analgesia and $\mathrm{S}=12$ minutes for Group $\mathrm{R}$, the sample size calculated was 74. After taking approval from Institutional Review Board, children between the age of 5 to 16 years, with ASA status I and II undergoing unilateral or bilateral herniotomy under general anaesthesia were included in the study. Children with neuro muscular disease, coagulopathy, and mentally retarded children were excluded. Children were shown Wong Baker pain scale day before surgery to familiarize them with pain scale. Eligible patients were randomized 1:1 using computer generated series. Allocation concealment was done using sealed envelope and the details were unknown to the investigator. Induction was done with Fentanyl at $2 \mathrm{mcg} / \mathrm{kg}$ and Propofol at $2 \mathrm{mg} / \mathrm{kg}$. For the patients who were apprehensive, intravenous cannulation was done under gaseous induction with Sevoflurane. If necessary, Propofol was added further till no movement on jaw thrust. Laryngeal mask airway (LMA) of appropriate size was inserted and its position was confirmed with bagging while looking for chest expansion and EtCO2 and maintenance of respiration was done with spontaneous ventilation. Maintenance of anaesthesia was done with Isoflurane $1.5-2 \%$ in oxygen. Caudal block was performed with landmark technique under aseptic precaution in lateral position after induction before the start of surgery. Group B received $0.25 \%$ Bupivacaine at $0.75 \mathrm{ml} / \mathrm{kg}$ whereas group $\mathrm{R}$ received $0.25 \%$ Ropivacaine at $0.75 \mathrm{ml} / \mathrm{kg}$. The heart rate, blood pressure and oxygen saturation (SPO2) were recorded as baseline, then at every 5 minutes after insertion of LMA for 60 minutes and thereafter every 10 minutes till surgery continue. After the completion of surgery, each patient was observed for 6 hours in the post-anaesthesia care unit. Pain was assessed using Wong Baker facial pain scale on arrival, at $30 \mathrm{~min}, 1 \mathrm{hr}, 2 \mathrm{hr}, 3 \mathrm{hr}, 4 \mathrm{hr}$ and $6 \mathrm{hr}$. The duration of absolute analgesia was defined as the time from caudal block till the administration of $1^{\text {st }}$ rescue analgesia with intravenous fentanyl. Rescue analgesia with Fentanyl $1 \mathrm{mcg} / \mathrm{kg}$ was given for a facial pain score of four or more. Motor block was assessed by using Modified Bromage scale on arrival, at $30 \mathrm{~min}, 1 \mathrm{hr}, 2 \mathrm{hr}, 3 \mathrm{hr}, 4 \mathrm{hr}$ and $6 \mathrm{hr}$.

All data were entered in Microsoft Office Excel Worksheet 2007. For the analysis of the data, Statistical package for the social sciences (SPSS) 17 was used. Unpaired t test was used for data analysis. $p$ value less than 0.05 were considered as significant.

\section{Results}

Total 74 children were enrolled in the study. Thirty seven patients received $0.25 \%$ Bupivacaine at $0.75 \mathrm{ml} / \mathrm{kg}$ (Group B) as caudal analgesia whereas the other 37 received $0.25 \%$ Ropivacaine at $0.75 \mathrm{ml} / \mathrm{kg}$ (Group R). The demographic profile of the patients in both groups is shown in table 1.

Table 1: Comparison of demographic distribution of groups

\begin{tabular}{|l|c|c|c|}
\hline $\begin{array}{c}\text { Demographic } \\
\text { distribution }\end{array}$ & $\begin{array}{c}\text { Bupiva- } \\
\text { caine } \\
\text { group }\end{array}$ & $\begin{array}{c}\text { Ropiva- } \\
\text { caine } \\
\text { group }\end{array}$ & p-value \\
\hline Mean age (yrs) & $6.46 \pm 1.89$ & $\begin{array}{c}7.08 \pm \\
2.15\end{array}$ & 0.191 \\
\hline $\begin{array}{l}\text { Sex distribution } \\
\text { (M:F) }\end{array}$ & $32: 5$ & $33: 4$ & \\
\hline $\begin{array}{l}\text { Mean weight } \\
\text { (Kg) }\end{array}$ & $\begin{array}{c}20.54 \pm \\
3.693\end{array}$ & $\begin{array}{c}21.91 \pm \\
4.38\end{array}$ & 0.41 \\
\hline ASA PS I & 37 & 37 & 1 \\
\hline
\end{tabular}

The duration of surgery in both the groups is shown in table 2. 
Table 2: Comparison of duration of surgery

\begin{tabular}{|c|c|c|c|}
\hline Characteristic & $\begin{array}{c}\text { Bupiva- } \\
\text { caine } \\
\text { group }\end{array}$ & $\begin{array}{c}\text { Ropiva- } \\
\text { caine } \\
\text { Group }\end{array}$ & p-value \\
\hline Mean duration of & $32.16 \pm$ & $33.24 \pm$ & 0.591 \\
surgery (mins) & 8.54 & 8.68 & \\
\hline
\end{tabular}

Data presented as mean $\pm S D$

The duration of absolute analgesia was the time from caudal block to administration of $1^{\text {st }}$ rescue analgesia. The rescue analgesia was given as intravenous fentanyl at $1 \mathrm{mcg} / \mathrm{kg}$ if pain score is 4 or more on Wong-Baker scale. The comparison of absolute analgesia between the groups is shown in Table 3.

Table 3: Comparison of duration of post operative analgesia

\begin{tabular}{|l|c|c|c|}
\hline \multicolumn{1}{|c|}{ Characteristic } & $\begin{array}{c}\text { Bupiva- } \\
\text { caine } \\
\text { group }\end{array}$ & $\begin{array}{c}\text { Ropiva- } \\
\text { caine } \\
\text { group }\end{array}$ & p-value \\
\hline $\begin{array}{l}\text { Mean duration of } \\
\text { absolute analgesia } \\
\text { (minutes) }\end{array}$ & $\begin{array}{c}253.51 \pm \\
11.48\end{array}$ & $\begin{array}{c}258.1 \pm \\
12.10\end{array}$ & 0.098 \\
\hline
\end{tabular}

Data presented as mean $\pm S D$

The consumption of rescue analgesia was noted over $6 \mathrm{hrs}$ in post operative period. The mean consumption of rescue analgesia in Bupivacaine group was $24.29 \pm 8.74 \mathrm{mcg}$ and $24.21 \pm 8.00 \mathrm{mcg}$ in Ropivacaine group (Table 4)

Table 4: Comparison of total consumption of rescue analgesia

\begin{tabular}{|c|c|c|c|}
\hline Characteristic & $\begin{array}{c}\text { Bupiva- } \\
\text { caine } \\
\text { group }\end{array}$ & $\begin{array}{c}\text { Ropiva- } \\
\text { caine } \\
\text { group }\end{array}$ & p-value \\
\hline $\begin{array}{c}\text { Mean consumption } \\
\text { of Fentanyl (mcg) }\end{array}$ & $\begin{array}{c}24.29 \pm \\
8.74\end{array}$ & $\begin{array}{c}24.21 \pm \\
8.00\end{array}$ & 0.50 \\
\hline
\end{tabular}

The degree of motor power was assessed using 4 point Modified Bromage scale in post operative period after completion of surgery. The median duration of motor block was defined as time interval once the patient arrived in post anaesthesia care unit till complete recovery of motor power (Modified Bromage scale of 0 ). The comparison of duration of motor block between Group B and Group $\mathrm{R}$ is shown in table 5.
Table 5: Comparison of duration of motor block between groups

\begin{tabular}{|c|c|c|c|}
\hline Characteristic & $\begin{array}{c}\text { Bupiva- } \\
\text { caine } \\
\text { group }\end{array}$ & $\begin{array}{c}\text { Ropiva- } \\
\text { caine } \\
\text { group }\end{array}$ & p-value \\
\cline { 1 - 3 } $\begin{array}{c}\text { Duration of motor } \\
\text { block (minutes) }\end{array}$ & 180 & 30 & \multirow{2}{*}{$<0.001^{*}$} \\
\cline { 1 - 3 } Q1 & 60 & 22.5 & \\
\cline { 1 - 3 } & 180 & 45 & \\
\hline
\end{tabular}

Data presented as median, $Q$ = interquartile range, * $p$ value significant

At $2^{\text {nd }}$ hour in post operative period, complete recovery of motor power was seen in all patients in Group $\mathrm{R}$, whereas all the patients had complete motor power recovery at $4^{\text {th }}$ hour in Group B.

Complications such as nausea, vomiting and urinary retention were not seen in any of the patients during the study period.

\section{Discussion}

The regional anaesthesia technique is preferred over opioids for control of postoperative pain as it decreases the side effects due to opioid sparing effect. Meta analysis has shown that caudal block is superior to other form of regional technique for providing analgesia requiring less rescue dose $\mathrm{e}^{5}$.

The primary objective of our study was to compare $0.75 \mathrm{ml} / \mathrm{kg}$ of $0.25 \%$ Ropivacaine and Bupivacaine via caudal route in term of duration post operative analgesia. Duration of motor block and any other side effects were also compared. The duration of absolute analgesia was defined as time from caudal injection to administration of first dose of IV Fentanyl $1 \mathrm{mcg} / \mathrm{min}$. The mean duration of absolute analgesia was $253.51 \pm 11.48$ minutes in Group B and $258.1 \pm 12.10$ minutes in Group $R$. There was no statistical difference between the two groups $(p=$ 0.098). The mean consumption of fentanyl was also similar in both groups $(24.29 \pm 8.74 \mathrm{mcg}$ in Group $B$ and $24.21 \pm 8.00 \mathrm{mcg}$ in Group $R, p$ value 0.50 ). In terms of analgesia, both caudal Ropivacaine and Bupivacaine were found to be equally effective. The studies done by Chipde et al. ${ }^{6}$, Ray et al. ${ }^{7}$ and Tambey et al. ${ }^{8}$ also showed that duration of analgesia provided by caudal Ropivacaine and Bupivacaine were similar. However studies by Locatell et al. ${ }^{9}$, Soujanya et al. ${ }^{10}$, and Sharma et al. ${ }^{11}$ showed significant longer duration of analgesia in Bupivacaine group. 
The degree and duration of motor block should also be taken into account in post-operative period as it is annoying to children with prolonged motor block in spite of good pain relief. In the studies by Locatelli et al. ${ }^{9}$ and Soujanya et al. ${ }^{10}$ where the prolonged duration of analgesia was recorded with Bupivacaine, the motor block was also significantly longer. The degree of motor block in our study was defined as time from arrival in post-anaesthesia care unit to complete motor recovery. As the data were not normally distributed, the median was used for measurement of central tendency for duration of motor block in our study. The median duration of motor block in Group B was 180 minutes (Q1 60- Q3 180) and in Group R was 30 minutes (Q1 22.5-Q3 45). The result was statistically significant $(p<0.001)$. In Group R all the patients had complete motor recovery by 2 hours and in Group B by 4 hours ( $p$ value $<0.001$ ). The lesser duration of motor block by Ropivacaine is consistent with study by Ray et al. ${ }^{7}$. The study done by Chipde et al. ${ }^{6}$ showed the complete recovery of motor power by 4 hour in Ropivacaine group where as there was still some residual block left in some patients in Bupivacaine group. In other study done by Soujanya et al. ${ }^{10}$, the mean duration of motor block was $101.0 \pm$ 18.02 minutes in Ropivacaine group and 133.53 \pm 45.5 minutes in Bupivacaine group. By 4 hours all patients in Ropivacaine group had complete recovery while some patients in Bupivacaine group still had some residual weakness. Both of these studies have used the volume of $1 \mathrm{ml} / \mathrm{kg}$ which is higher than our study. That may be the reason why the motor block was prolonged in their study compared to our study. The quick motor recovery in Ropivacaine may be due to its differential action on A delta fibers than A beta fibers ${ }^{11}$.

None of the patients in our study had any postoperative complications like nausea, vomiting or urinary retention.

\section{Conclusion}

Ropivacaine is equally effective as Bupivacaine for caudal analgesia in case of children with the added advantage of early recovery from motor weakness.

\section{References}

1. Callesen T, Bech K, Thorup J, Andersen J, Nielsen R, Roikjaer $\mathrm{O}$, et al. Cryoanalgesia: Effect on postherniorrhaphy pain. Anesth Analg. 1998;87(4):896-9.
2. Drendel AL, Kelly BT, Ali S. Pain assessment for children: Overcoming challenges and optimizing care. Pediatr Emerg Care. 2011;27(8):773-81.

3. Lönnqvist PA, Morton NS. Postoperative analgesia in infants and children. $\mathrm{Br} \mathrm{J}$ Anaesth. 2005;95(1):59-68.

4. Patel D. Epidural analgesia for children. Continuing Education in Anaesthesia Critical Care \& Pain. 2006;6(2):63-6.

5. Shanthanna H, Singh B, Guyatt G. A systematic reviewand meta-analysis of caudal block as compared to non caudal regional techinques for inguinal surgeries in children. Bio Med Research International. Volume 2014, Article ID 890626.

6. Chipde SS, Banjare M, Arora KK, Saraswat $M$. Prospective randomized controlled comparison of caudal bupivacaine and ropivacaine in paediatric patients. Ann Med Health Sci Res. 2014;4(4supp2):s115-s118.

7. Ray M, Mondal S K, Biswas A. Caudal analgesia in paediatric patients: Comparison between bupivacaine and ropivacaine. Indian J Anaesth. 2003;47:275-8.

8. Tambey $\mathrm{R}$ et al. Caudal epidural ropivacaine versus bupivacaine in pediatric patients for infra-umbilical surgeries. Int J Health Sci Res. 2015;5(6):123-33.

9. Locatelli $B$, Ingelmo P, Sonzogni $V$, Zanella A, Gatti V, Spotti A, Di Marco S, Fumagalli R. Randomized, double-blind, phase III, controlled trial comparing levobupivacaine $0.25 \%$, ropivacaine $0.25 \%$ and bupivacaine $0.25 \%$ by the caudal route in children. $\mathrm{Br} \mathrm{J}$ Anaesth. 2005;94(3):366-71.

10. Uma Soujanya.S, Sravanthi.B, A.S Kameswara. Rao. A comparison between levobupivacaine, ropivacaine and bupivacaine in caudal anaesthesia in children undergoing lower abdominal surgeries. Indian Journal of Basic and Applied Medical Research. 2015;4(4):654-61.

11. Sharma J, Gupta R, Kumari A, Mahajan L, Singh J. A comparative study of $0.25 \%$ levobupivacine, $0.25 \%$ ropivacaine, and $0.25 \%$ bupivacaine in paediatric single shot caudal block. Anesthesiology research and practice. Volume 2018, Article ID 1486261. 